\title{
Preparation of Pt-Ru bimetallic catalyst supported on carbon nanotubes
}

\author{
B RAJESH, K RAVINDRANATHAN THAMPI ${ }^{\dagger}$, J -M BONARD ${ }^{\ddagger}$ and B VISWANATHAN* \\ Department of Chemistry, Indian Institute of Technology, Chennai 600 036, India \\ ${ }^{\dagger}$ Laboratoire de Photonique, ${ }^{\ddagger}$ Institut de Physique et Interfaces, Ecole Polytechnique Federale de Lausanne, \\ CH-1015, Switzerland
}

MS received 18 March 2000

\begin{abstract}
The template carbonization of polyphenyl acetylene yields hollow, uniform cylindrical carbon nanotubes with outer diameter almost equal to pore diameter of the template used. High resolution transmission electron microscopic investigation reveals that Pt-Ru nanoparticles are highly dispersed inside the tube with an average particle size of $1.7 \mathrm{~nm}$.
\end{abstract}

Keywords. Carbon nanotubes; template synthesis; fuel cell catalyst; nanoparticles.

\section{Introduction}

There is a considerable interest currently in developing nanostructured materials, as they find potential application in various fields of materials research (Bein and Stucky 1996). Among these, carbon nanotubes and filled carbon nanotubes find application in nano electronic devices, as tips in atomic force microscope (Dai et al 1996), as possible catalyst support materials in heterogeneous catalysis (Rodriguez et al 1994) and in fuel cells (Che et al 1999), as hydrogen storage materials (Baum 1997) and other gases (Gadd et al 1997). The discovery of carbon nanotube (Iijima 1991) was first based on the carbon-arc method, though the carbon nanotube prepared by this method are more graphitic, the low yield and relatively small length $(<1 \mathrm{~m})$ make the production cost very high. The template synthesis method (Martin 1994) and catalytic production methods (Jose et al 1993) avoid some of these difficulties. The yield obtained in catalytic production method is high compared to that of the carbonarc method. Unfortunately there are also some drawbacks. The catalytically fabricated tubules are thicker than those obtained by the arc-discharge process and are covered by a thick layer of amorphous carbon. Among the different strategies employed to synthesize the nanostructured materials, template synthesis is an elegant approach. The template aided synthesis of nanostructured materials takes into consideration size control, shape and purity of the resulting nanostructured material, as the growth of the nanomaterial is arrested by the restricted dimension imposed by the template. This technique was first perfected by Martin (Parthasarathy and Martin 1994)

\footnotetext{
*Author for correspondence
}

to synthesize the desired materials within the pores of the template membrane with cylindrical pore of uniform diameter and have been used to make nanotubules and fibres composed of polymers (Van Dyke and Martin 1990; Cepuk and Martin 1999), carbon (Che et al 1998), metal(s) (Martin 1996), semiconductors (Lakshmi et al 1997) and metal oxides (Sen et al 1999; Imai et al 1999).

The general source of carbon to produce the carbon nanotubes are hydrocarbons (Hernadi et al 1994; Kyotani et al 1995; Hafner et al 1998), but the complexity involved in the synthesis of carbon nanotubes using gaseous hydrocarbon is high, so an alternative and easy way should be employed to synthesize this material avoiding gaseous and toxic hydrocarbons. Polymers such as polyacrylonitrile (Parthasarathy et al 1995) and polyfurfuryl alcohol (Kyotani et al 1996) have been used as the carbon source to prepare carbon nanotubes. The criteria of selecting the carbon precursor is that, it should be rich in carbon and it should be easily decomposed to leave the pure carbon deposit.

In this communication, we report the use of polyphenyl acetylene as the carbon source to prepare carbon nanotubes. Since it has a rich source of carbon and only carbonhydrogen bonds have to be broken during the thermal treatment, it can be a good source to prepare the carbon deposits on the walls of nanoporous alumina membrane which is used as the template. We have also attempted to prepare platinum-ruthenium encapsulated carbon nanotubule, as the supported bimetallic catalyst finds application in direct methanol fuel cells.

\section{Experimental}

The polyphenyl acetylene has been prepared based on (Gita and Sundararajan 1994) photoinduction of phenyl- 
acetylene by $\mathrm{W}(\mathrm{CO})_{6}$. The polyphenyl acetylene/alumina composite was prepared by placing $10 \mathrm{ml}$ of $5 \% \mathrm{w} / \mathrm{w}$ polyphenyl acetylene (in dichloro methane) on the alumina membrane (Whatman, $200 \mathrm{~nm}$ pore diameter, $60 \mu \mathrm{m}$ thick, $17.34 \mathrm{~cm}^{2}$ ) and slowly vacuum was applied from the bottom. By applying the vacuum, the entire polymer solution penetrate inside the pores of the template mem- brane. The solvent was evaporated slowly and dried in vacuum at $60^{\circ} \mathrm{C}$. The composite was then polished with fine alumina powder to remove the surface layers and ultrasonicated for $20 \mathrm{~min}$ to remove the residual alumina used for polishing. The infrared spectroscopy confirms the presence of polyphenyl acetylene in the membrane. The composite was then carbonized at $900^{\circ} \mathrm{C}$ at $10^{\circ} \mathrm{C} / \mathrm{min}$
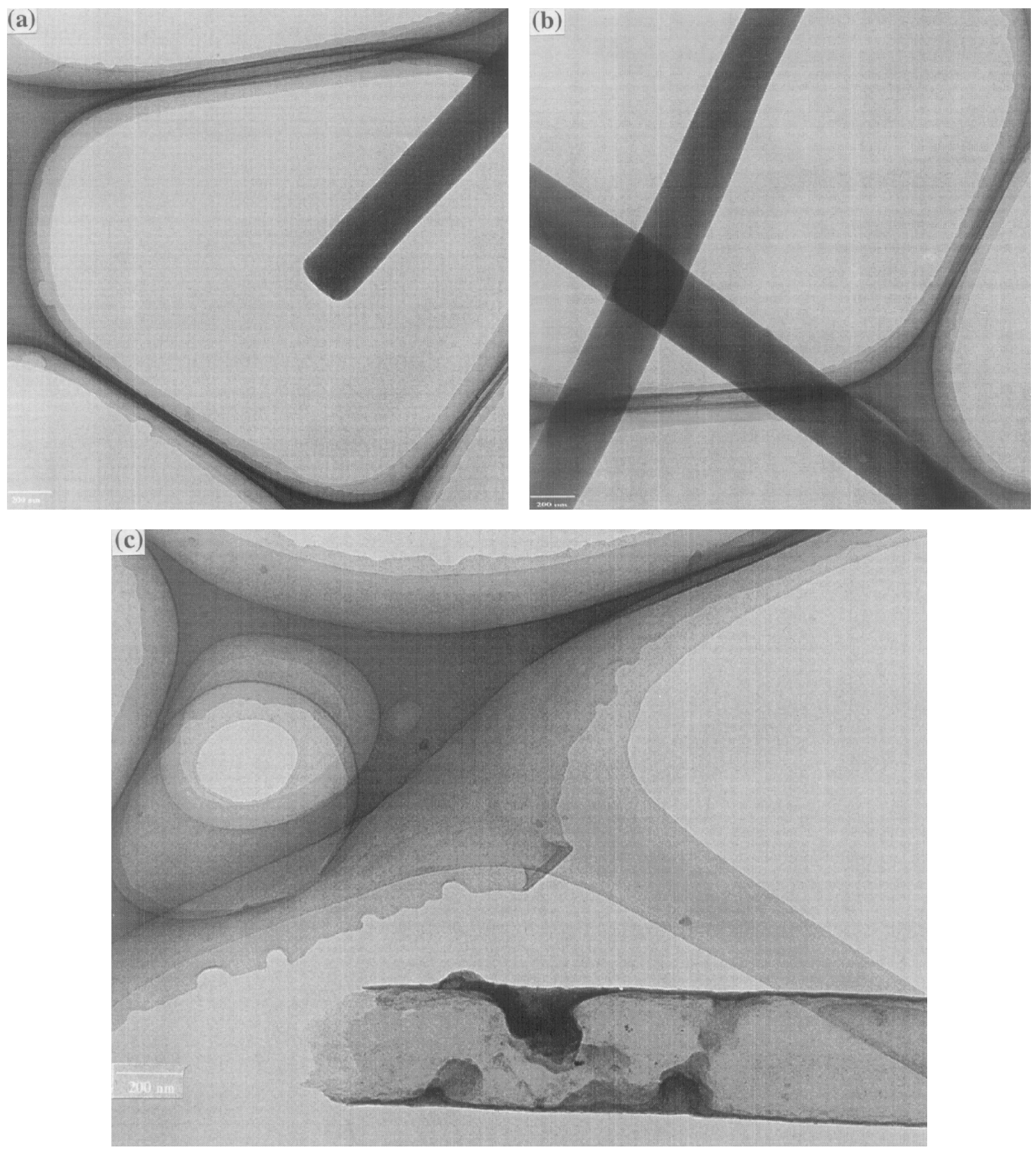

Figure 1. High resolution transmission electron micrographs showing a-b. the cylindrical, monodisperse, uniform carbon nanotubes obtained by carbonization of polyphenyl acetylene on alumina membrane with the outer diameter $\sim 200 \mathrm{~nm}$ and c. the tube to be transparent which indicates the thin wall thickness of the carbon nanotube. The open end allowed to disperse the nanoparticles inside. 

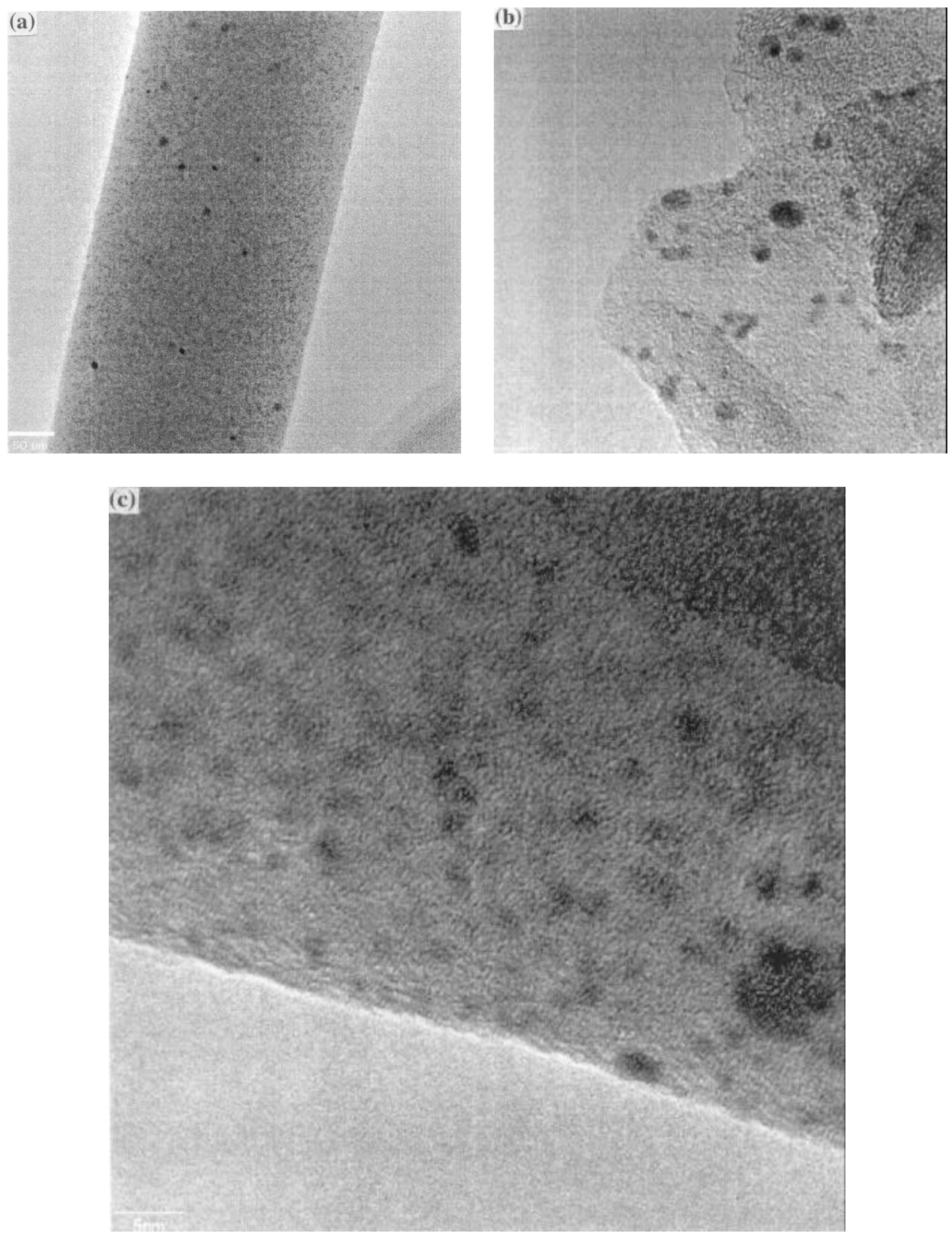

Figures 2. a-c. The HR-TEM images of bimetallic Pt-Ru nanoparticles dispersed on the nanotube. The average particle size was found to be $1.7 \mathrm{~nm}(\mathbf{c})$. 
for $3 \mathrm{~h}$ in $\mathrm{Ar}$ atmosphere which resulted in the deposition of carbon on the channel walls of the template membrane. The carbon/alumina composite was then dissolved in $48 \% \mathrm{HF}$ to free the nanotubules. The tubules were completely washed with deionized water to remove the HF.

The platinum-ruthenium bimetallic nanoparticles filled carbon nanotubes were prepared by immersing the carbon/ alumina composite (after the carbonization of polyphenyl acetylene) in $37 \mathrm{mM} \mathrm{H}_{2} \mathrm{PtCl}_{6}(\mathrm{aq})$ and $73 \mathrm{mM} \mathrm{RuCl}_{3}(\mathrm{aq})$ for $5 \mathrm{~h}$ to allow the salts to penetrate inside the nanotube. The composite was then dried at room temperature and reduced in a flow of $\mathrm{H}_{2}$ at $550^{\circ} \mathrm{C}$ for $3 \mathrm{~h}$. The membrane was dissolved in $48 \% \mathrm{HF}$ for $24 \mathrm{~h}$ to leave $\mathrm{Pt}-\mathrm{Ru}$ nanoparticles filled carbon nanotube. The carbon nanotubules and the platinum-ruthenium filled tubules were dispersed in ethanol under sonication and dropped on the carbon-coated grid for transmission electron microscopic (TEM, Phillips EM430ST) investigation operated at $300 \mathrm{kV}$.

\section{Results and discussion}

High resolution TEM pictures shown in figures $1 \mathrm{a}-\mathrm{b}$ indicate the formation of cylindrical, monodisperse tube with a outer diameter of almost $200 \mathrm{~nm}$ which corresponds to the channel diameter of the template used. It is noteworthy from figure $1 \mathrm{c}$ that the tubes are transparent under TEM observation, indicating the wall thickness to be very thin. It is also seen from the figure, that the tube ends are opened which can be utilized to load the nanoparticles inside. Though the carbon tubes produced by this method are not completely graphitic as produced by arc-discharge process, their disordered structure is quite typical of fibres or nanotubes produced by decomposition of hydrocarbon.

Figures $2 \mathrm{a}-\mathrm{c}$ show that the platinum and ruthenium nanoparticles are highly dispersed inside the carbon nanotube with an average particle size of around $1.7 \mathrm{~nm}$. The open end structure of the tube has been confirmed by the presence of most of the bimetallic nanoparticles inside the tube, though some of them are also embedded in the wall.

\section{Conclusion}

The template carbonization of polyphenyl acetylene results in an easy way of producing uniform, hollow and cylindrical carbon nanotubes. The open ends of the tube were allowed to load bimetallic Pt-Ru nanoparticles inside, which can be used as possible electrocatalyst material in fuel cells. The metallic particles strongly entrapped inside the tube is reflected by the fact that the particles appear to be quite stable even after the vigorous treatment of the composite in concentrated HF.

\section{Acknowledgements}

The authors sincerely thank the Head and Director, Prof. Michael Gratzel, Labatoire De Photonique Et Interfaces (LPI), for providing laboratory facilities to carry out this work at Ecole Polytechnique Federale De Lausanne (EPFL), Switzerland. We thank the Centre Interdepartmental de Microscopic Electronique (CIME) at EPFL for access to electron microscopes.

\section{References}

Baum R M 1997 Chem. Eng. News 7539

Bein T and Stucky G D 1996 Chem. Mater. 81569

Cepuk V M and Martin C R 1999 Chem. Mater. 111363

Che G, Lakshmi B B, Martin C R and Fisher E R 1998 Chem. Mater. 10260

Che G, Lakshmi B B, Martin C R and Fisher E R 1999 Langmuir 15750

Dai H, Hafner J H, Rinzeler A G, Collbert D T and Smalley R E 1996 Nature 384147

Dai H, Wony E W and Leiber C M 1996 Science 272523

Gadd G E et al 1997 Science 277933

Gita B and Sundararajan G 1994 Am. Chem. Soc. Div. Polym. 35729

Hafner J H, Branikowski M J, Azamian B R, Nikalov P, Rinzler A G, Colbert D T, Smith K A and Smalley R E 1998 Chem. Phys. Lett. 296195

Hernadi K, Fonseca A, Nagy J B, Bernath D, Riya J, Lucas A, Huttu N and Muratu K J 1994 Chem. Phys. Lett. 217398

Iijima S 1991 Nature 35456

Imai H, Takei Y, Shimizu K, Matsudu M and Horushimu H 1999 J. Mater. Chem. 92971

Jose-Yacamen M, Miki-Yoshida M, Rendan L and Santiesteban J G 1993 Appl. Phys. Lett. 62657

Kyotani T, Tsui L and Tomita A 1995 Chem. Mater. 71427

Kyotani T, Tsui L and Tomitu A 1996 Chem. Mater. 82109

Lakshmi B B, Dorhout P K and Martin C R 1997 Chem. Mater. 9857

Martin C R 1994 Science 2661961

Martin C R 1996 Chem. Mater. 81739

Parthasarathi R V and Martin C R 1994 Nature 369298

Parthasarathy R V, Phani K L N and Martin C R 1995 Adv. Mater. 7898

Rodriguez N M, Kim M S and Baker R T K 1994 J. Phys. Chem. 9813108

Sen R et al 1999 J. Mater. Chem. 72335

Van Dyke L S and Martin C R 1990 Langmuir 61118 